\title{
Vitamin D in Type 2 Diabetes: Genetic Susceptibility and the Response to Supplementation
}

\section{(๑) $\odot \Theta$}

Authors

Edith Klahold ${ }^{1}$, Marissa Penna-Martinez ${ }^{1 *}$, Franziska Bruns ${ }^{1}$, Christian Seidl$^{2}$, Sabine Wicker ${ }^{3}$, Klaus Badenhoop $^{1 *}$

Affiliations

1 Department of Internal Medicine I, Division of Endocrinology, Diabetes and Metabolism, Goethe-University Hospital, Frankfurt/Main, Germany

2 German Red Cross Blood Donor Service, Institute for Transfusion Medicine and Immunohaematology, Frankfurt/Main, Germany

3 Occupational Health Service, Goethe-University Hospital, Frankfurt/Main, Germany

Key words

CYP2R1, CYP27B1, DBP, VDR, CYP24A1, GC

received $\quad 15.03 .2019$

accepted 07.04.2020

published online 15.6 .2020

Bibliography

Horm Metab Res 2020; 52: 492-499

DOI 10.1055/a-1157-0026

ISSN 0018-5043

(c) 2020. The Author(s).

This is an open access article published by Thieme under the terms of the Creative Commons Attribution-NonDerivative-NonCommercial-License, permitting copying and reproduction so long as the original work is given appropriate credit. Contents may not be used for commercial purpose, or adapted, remixed, transformed or built upon. (https://creativecommons. org/licenses/by-nc-nd/4.0/)

Georg Thieme Verlag KG, Rüdigerstraße 14,

70469 Stuttgart, Germany

Correspondence:

Edith Klahold

Department of Internal Medicine I, Division of Endocrinology,

Diabetes and Metabolism, Goethe-University Hospital

Theodor-Stern-Kai 7

60590 Frankfurt/Main

Germany

Tel.: + 49696301 83977, Fax: + 4969630183343

eklahold@gmx.de $\circledast$ Supplementary Material for this article is available online at http://www.thieme-connect.de/products.

\begin{abstract}
Variants of vitamin D metabolism-genes may predispose to type 2 diabetes (T2D). This study investigated the impact of these variants on disease susceptibility, Vitamin $D$, parathyroid hormone, C-peptide and HbA1c levels before and after cholecalciferol supplementation in patients with T2D. Twelve polymorphisms within CYP2R1, CYP27B1, DBP, VDR and CYP24A1 were genotyped in 553 T2D patients and 916 controls. In addition 65 patients receiving either cholecalciferol or placebo were analyzed during 6 months intervention and 6 months follow-up. T2D risk alleles are VDR rs7975232 “ $G$ ” ( $\left.p_{c}=0.031\right)$, rs1544410 "G" ( $\left.p_{c}=0.027\right)$ and CYP2R1 rs10741657 "A" $\left(p_{c}=0.016\right)$. Patients with genotypes CYP27B1 rs10877012 "CC" $\left(\mathrm{p}_{\mathrm{c}}=4 \times 10^{-5}\right)$, DBP rs7041 “GG” ( $\left.\mathrm{p}_{\mathrm{c}}=0.003\right), \mathrm{rs} 4588$ “CC" $\left(\mathrm{p}_{\mathrm{c}}=\right.$ $\left.3 \times 10^{-4}\right), C Y P 24 A 1$ rs 2585426 "CG" $\left(p_{c}=0.006\right)$ and $r s 2248137$ "CG" $\left(\mathrm{p}_{\mathrm{c}}=0.001\right)$ showed lower $25(\mathrm{OH}) \mathrm{D}_{3}$ and DBP rs4588 "CC" lower $1,25(\mathrm{OH})_{2} \mathrm{D}_{3}$ levels $\left(\mathrm{p}_{\mathrm{c}}=0.005\right)$. Whereas DBP rs 4588 "CC" $\left(p_{c}=0.009\right), C Y P 27 B 1$ rs10877012 “AC" $\left(p_{c}=0.059\right), V D R$ rs7975323 "AG" ( $\left.p_{c}=0.033\right)$ and rs1544410 "GG" ( $\left.p_{c}=0.013\right)$ are associated with higher $25(\mathrm{OH}) \mathrm{D}_{3}$ levels at 6 months' follow-up. Significant PTH suppression was detected for CYP2R1 "AG" ( $\left.\mathrm{p}_{\mathrm{c}}=0.002\right)$, DBP rs4588 “CC" $\left(\mathrm{p}_{\mathrm{c}}<0.001\right)$, VDR rs110735810 "CT" ( $\left.p_{c}<0.001\right)$ and CYP24A1 rs2248137 "GC" $\left(p_{c}=0.021\right)$. Genetic variants of the vitamin $D$ system predispose to type 2 diabetes and regulate - partially - vitamin D metabolism, concentrations and the vitamin D status. Vitamin D insufficiency is a T2D risk factor. The response to cholecalciferol supplementation can be measured as $25(\mathrm{OH}) \mathrm{D}_{3}$ increment and PTH suppression. This process is regulated by genes of the vitamin D system conferring modest T2D risk.
\end{abstract}

\footnotetext{
* equal contribution Penna-Martinez \& Badenhoop
} 


\section{Introduction}

Vitamin D (VD) insufficiency impairs glucose homeostasis and confers susceptibility to type 2 diabetes (T2D) [1]. The VD status reflects endogenous synthesis via UVB irradiation, dietary intake, and genetic background [2]. The liver enzyme CYP2R1 25-hydroxylase converts vitamin $D_{3}$, obtained from previtamin $D_{3}$ isomerization, into $25(\mathrm{OH}) \mathrm{D}_{3}$, which is the major circulating VD metabolite and indicates the VD status [3]. Circulating VD metabolites are mainly bound to vitamin D binding protein (DBP, also known as GC group-specific component). The $\mathrm{D}_{3}-1 \alpha$-hydroxylase (CYP27B1) catalyzes the activation to $1,25(\mathrm{OH})_{2} \mathrm{D}_{3}$ in the kidney and macrophages [4]. 1,25(OH) ${ }_{2} \mathrm{D}_{3}$, activates the vitamin $\mathrm{D}$ receptor (VDR), which regulates the expression of genes with a vitamin $D$ response element [5]. Finally, VD is degraded via 24-hydroxylation catalyzed by 25-hydroxyvitamin D 24-hydroxylase (CYP24A1) [6].

Besides environmental factors also genetic variation in the VD system as defined by single nucleotide polymorphisms (SNPs) influences VD serum levels [7].

The purpose of this study was to investigate VD system SNPs in T2D patients, whether they specifically regulate the basal VD status and its response to supplementation. Twelve SNPs of the VD system genes CYP2R1 (rs10741657), CYP27B1 (rs10877012), DBP (rs4588, rs7041), VDR (rs7975232, rs731236, rs2228570, rs1544410), CYP24A1 (rs2582426, rs927650, rs2296241, rs2248137) were analyzed in a case-control design. These SNPs were correlated with $25(\mathrm{OH}) \mathrm{D}_{3}, 1,25(\mathrm{OH})_{2} \mathrm{D}_{3}$, parathyroid hormone $(\mathrm{PTH})$, C-Peptide, and $\mathrm{HbA} 1 \mathrm{c}$ concentrations in an interventional trial where patients with $\mathrm{T} 2 \mathrm{D}$ had been supplemented with $\mathrm{VD}_{3}$.

\section{Patients and Methods}

\section{SNPs of the VD system: T2D susceptibility and the VD status}

A case-control cohort study was conducted to investigate an association of VD system SNPs with T2D. Data from up to 553 T2D patients and 916 healthy controls were available, but sufficient DNA for genotype analysis only in 464 patients (209 women and 255 men) and 292 (138 women and 154 men) controls.

Patients were recruited from the Endocrine \& Diabetes Clinic, healthy controls from the Occupational Health service of the University Hospital in Frankfurt/Main and the Blood Donor Service. $25(\mathrm{OH}) \mathrm{D}_{3}$ and $1,25(\mathrm{OH})_{2} \mathrm{D}_{3}$ concentrations were available for 62 ( 31 women and 31 men) patients and 73 ( 38 women and 35 men) healthy controls.

\section{VD intervention study}

This preliminary pharmacogenetic analysis was conducted on samples from a recently published randomized trial [8], which investigated the effects of $\mathrm{VD}_{3}$ treatment in T2D. Sixty-seven patients had been recruited ( 15 women, 18 men in therapy group and 16 women, 18 men in placebo group) to receive either Vigantol $\left(\mathrm{VD}_{3}, 20 \mathrm{drops} /\right.$ week, $1904 \mathrm{lU} / \mathrm{d}$ ) or placebo oil for 6 months and were followed for 6 months.

\section{Clinical parameters}

Parameters were analyzed initially and after every three months until the trial's observational end at 12 months. $25(\mathrm{OH}) \mathrm{D}_{3}(\mathrm{ng} / \mathrm{ml})$ and $1,25(\mathrm{OH})_{2} \mathrm{D}_{3}(\mathrm{pg} / \mathrm{ml})$ concentrations were measured by radioimmunoassay (RIA), PTH (pg/ml) and C-Peptide $(\mathrm{ng} / \mathrm{ml})$ by solid phase chemiluminescence assay (CLIA), and $\mathrm{HbA} 1 \mathrm{c}(\mathrm{mmol} / \mathrm{mol})$ by spectrophotometric method.

\section{Vitamin D system genes and SNPs}

Twelve SNPs in five genes were investigated: CYP2R1 (rs10741657), CYP27B1 (rs10877012), DBP (rs4588, rs7041), VDR (rs7975232, rs731236, rs2228570, rs1544410), and CYP24A1 (rs285426, rs927659, rs2296241, rs2248137).

Genomic DNA was extracted from whole blood by salting out [9]. Restriction fragment length polymorphism (RFLP) and real-time polymerase chain reaction (rtPCR) were used for genotyping. Restriction enzymes were used according to the manufacturer's instructions (New England Biolabs, Frankfurt/Main, Germany). Digestions products were separated on $3 \%$ agarose gel and visualized by ethidium bromide staining. RtPCR analysis was conducted in Taqman (ABI7300 system) under manufacturer's conditions (Applied Biosystems, Darmstadt, Germany). To confirm accuracy, random samples of all SNPs were genotyped twice with a concordance of $100 \%$.

\section{Statistical analysis}

All statistical analyses were performed using Bias for Windows 10.01. Non parametric testing was chosen for the metabolic parameters due to a non-Gaussian distribution ( $p \leq 10^{-4}$ in ShapiroWilk-test). Statistical significance was defined as $p \leq 0.05$.

\section{SNPs within the VD system genes and VD status}

Kruskal-Wallis-test was applied for the genetic effects on $25(\mathrm{OH})$ $\mathrm{D}_{3}$ and $1,25(\mathrm{OH})_{2} \mathrm{D}_{3}$ concentrations. For each SNP a global test, comparing patients and controls, was conducted first. In case of a significant result each genotype of this SNP was compared separately. Additionally the tests for a higher risk of VD insufficiency and the SNPs were performed by $\mathrm{Chi}^{2}$-test comparing the frequency of VD insufficient individuals between patients an healthy controls.

Bonferroni correction considered the number of SNPs in this gene (CYP2R1: 1, CYP27B1: 1, DBP: 2, VDR: 4, CYP24A1: 4), genotypes within one gene (3) and the amount of analyzed parameters (2).

\section{VD system SNPs and T2D susceptibility}

Tests for the impact of VD insufficiency on T2D risk was performed by Chi²-test comparing the frequency of VD insufficient and VD sufficient individuals in our cohort study according to the status of disease. T2D susceptibility was investigated using $\mathrm{Chi}^{2}$-test comparing the SNP distribution between patients and healthy controls. To allow multiple testing, all $p$-values were Bonferroni corrected $\left(p_{c}\right)$ considering the number of genotypes (3) or alleles (2) and the amount of analyzed genes (12).

\section{VD intervention trial}

Changes in $25(\mathrm{OH}) \mathrm{D}_{3}, 1,25(\mathrm{OH})_{2} \mathrm{D}_{3}$, PTH, C-Peptide, and HbA1c concentrations during $\mathrm{VD}_{3}$ supplementation were examined by Kruskal-Wallis-test comparing therapy and placebo group for each 
genotype and study visit. For analysis of intervention associated changes of metabolic parameters within one genotype Friedmann-test was used. Bonferroni-correction was performed considering the parameters (5), genotypes (3) and number of study visits during intervention/ follow-up (4).

\section{Results}

\section{VD and T2D risk}

Patients showed overall lower $25(\mathrm{OH}) \mathrm{D}_{3}$ and $1,25(\mathrm{OH})_{2} \mathrm{D}_{3}$ concentrations compared to healthy controls $\left[25(\mathrm{OH}) \mathrm{D}_{3}: 18.00 \mathrm{vs} .12 .25\right.$ $\mathrm{ng} / \mathrm{ml}, \mathrm{p}=7 \times 10^{-4} ; 1,25(\mathrm{OH})_{2} \mathrm{D}_{3}: 51.00$ vs. $\left.44.95 \mathrm{pg} / \mathrm{ml} \mathrm{p}=0.001\right]$. $25(\mathrm{OH}) \mathrm{D}_{3}$ concentration is the standard parameter representing the individual VD status [10]. In our cohort study, VD insufficiency $\left[25(\mathrm{OH}) \mathrm{D}_{3}<20 \mathrm{ng} / \mathrm{ml}\right]$ increases the risk of T2D by odds ratio (OR) 13.9 (confidence interval $(\mathrm{Cl}) 4.8-39.2, \mathrm{p}<0.001$ ).

\section{VD system genes predispose to T2D}

All genotyping data were in Hardy-Weinberg Equilibrium ( $p>0.05$ ) for each SNP. VDR rs7975232 allele "G" [40.6\% vs. 47.0\%; OR: 1.30, $\left.\mathrm{Cl}: 1.05-1.60, \mathrm{p}_{\mathrm{c}}=0.034\right]$ was more frequent in T2D and there was a trend for VDR rs 1544410 allele "G" (52.6\% vs. $57.9 \%$; OR: 1.24 , $\left.\mathrm{Cl}: 1.01-1.53, \mathrm{p}_{\mathrm{c}}=0.098\right)$. These results were validated testing all samples available for that gene (VDR rs7975232 "G": $43.2 \%$ vs. 48.0\%; OR: 1.21, 95\% Cl: 1.04-1.41, $\mathrm{p}_{\mathrm{c}}=0.031$, and VDR rs 1544410 "G": 53.9\% vs. 58.7\%; OR: 1.12, Cl: 1.04-1.41, $\left.\mathrm{P}_{\mathrm{c}}=0.027\right)$. Furthermore, the "A" allele of CYP2R1 rs10741657 (36.3\% vs. $42.1 \%$; OR: $\left.1.28, \mathrm{Cl}: 1.07-1.53, \mathrm{p}_{\mathrm{c}}=0.016\right)$ was more frequent among patients (॰ Table 1).

\section{VD system genes affect the VD metabolism in patients with T2D}

VD status and SNPS

VD insufficiency was observed in 101 and VD sufficiency in 34 individuals. None of the analyzed SNPs showed a significant association to the individual's VD status ( $\triangleright$ Table 1 ).

\section{VD status and T2D associated SNPs}

The VDR rs7975232 “G”, VDR rs1544410 “G”, and CYP2R1 rs10741657 "A" were associated with a higher T2D risk. The SNP dependent risk for T2D was analyzed in relation to VD insufficiency. This analysis did not reveal any significant impact of the three SNPs on T2D risk in this subgroup (Supplement $>$ Table 1S).

\section{Vitamin D level and T2D}

Analyses of VD status allow a risk-calculation but to quantify the difference of VD levels between T2D and controls a testing based on VD concentrations is necessary. To screen for SNPs that are specifically associated with lower VD concentrations in T2D patients a lower $p$-value was applied $(p<0.01)$. That way the specificity is raised and the per se lower VD concentrations in patients compared to controls are taken into account.

Lower $25(\mathrm{OH}) \mathrm{D}_{3}$ concentrations were detected for the genotypes CYP27B1 rs10877012 “CC" ( $\left.\mathrm{p}_{\mathrm{c}}=4 \times 10^{-5}\right)$, DBP rs7041 “GG" $\left(p_{c}=0.0003\right), r s 4588$ “CC” $\left(p_{c}=3 \times 10^{-4}\right), C Y P 24 A 1$ rs2585426 “CC” $\left(p_{c}=0.006\right)$, and rs2248137 “CG” ( $\left.p_{c}=0.001\right)$. Additionally, the DBP genotype rs4588 “CC" showed lower $1,25(\mathrm{OH})_{2} \mathrm{D}_{3}$ concentrations $\left(\mathrm{p}_{\mathrm{c}}=0.005\right)(\triangleright$ Table 2$)$.

\section{VD system genes affect the response to Vitamin $D_{3}$ supplementation}

Sixty-five participants in the interventional study were genotyped and - with an exploratory intention - analyzed for changes in $25(\mathrm{OH}) \mathrm{D}_{3}, 1,25(\mathrm{OH})_{2} \mathrm{D}_{3}$, PTH, C-Peptide, and HbA1c. The following genotypes showed continuously higher $25(\mathrm{OH}) \mathrm{D}_{3}$ concentrations till 6 months' follow-up compared to placebo (significant/ trend): CYP27B1 rs10877012 “AC" (18.80 vs. 13.85, $\left.\mathrm{p}_{\mathrm{c}}=0.059\right)$, DBP rs4588 “CC" (18.80 vs. 10.50, $\left.\mathrm{p}_{\mathrm{c}}=0.086\right)$, VDR rs7975232 “AG" (20.00 vs. 10.90, $\left.\mathrm{p}_{\mathrm{c}}=0.034\right)$ and VDR rs1544410 "GG" (21.10 vs. $9.90, \mathrm{p}_{\mathrm{c}}=0.013$ ) whereas the genotype CYP24A1 rs2296241 "GG" did not show any significant difference for the response to $\mathrm{VD}_{3}$ supplementation any time (Supplement $>$ Table 2S).

PTH was significantly suppressed during intervention in carriers of the genotypes CYP2R1 "AG" (median difference (MD) 12.0, Cl 5.0-21.0, $\mathrm{p}_{\mathrm{c}}=0.002$ ), DBP rs4588 “CC" (MD 14.5, Cl 8.0-24.0, $\mathrm{P}_{\mathrm{c}}<0.001$ ), VDR rs2228570 “TC" (MD 13.5, Cl 7.0-20.5, $\mathrm{p}_{\mathrm{c}}<0.001$ ), CYP24A1 rs927650 “TT” (MD 13.6, Cl 5.0-23.0, $\left.\mathrm{p}_{\mathrm{c}}=0.045\right)$, CYP24A1 rs2296241 “AG” (MD13.03, Cl 7.00-20.50, $\left.\mathrm{p}_{\mathrm{c}}=0.005\right)$ and CYP24A1 rs2248137 "CC" (MD 14.5, Cl 6.3-25.0, $\mathrm{p}_{\mathrm{c}}=0.021$ ).

For changes in $1,25(\mathrm{OH})_{2} \mathrm{D}_{3}, \mathrm{C}$-Peptide or $\mathrm{HbA}_{1 \mathrm{c}}$ there was no significant association to any investigated SNP (data not shown).

\section{Discussion and Conclusions}

In our cohort study, we find a higher risk for T2D conferred by CYP2R1 rs10741657 “A”, VDR rs7975232 “G”, and VDR rs1544410 "C". These two loci control VD synthesis (CYP2R1) and VD action (VDR). A recently published GWAS identified 143 risk variants for T2D in Europeans but none of the VD pathway [11] and a study from Norway did not find any association of CYP2R1 SNPs with T2D [12]. However a recently published Mendelian randomization study on more than 890000 individuals including the CYP2R1 SNP showed that genetically predicted higher $25(\mathrm{OH}) \mathrm{D}_{3}$ levels conferred significant protection from T2D [13]. Since genetic associations do not explain a cause-effect relation, the functional explanation for the observed effects might be due to linkage of the analyzed SNPs with other causal genes. The detection of such genes would guide to pathways of interest.

For $25(\mathrm{OH}) \mathrm{D}_{3}$ levels associations with CYP2R1 genotypes were established by GWAS and large scale population studies [14,15] while there was no effect on VD concentrations in our small amount of patients with T2D. The CYP2R1 gene codes for the key enzyme in the vitamin $\mathrm{D}$ metabolism for the 25 -hydroxylation. How a variant of this gene, which is located near the 3'UTR affects a different function remains unclear. Potential explanations include changes in enzyme activity resulting in lower $25(\mathrm{OH}) \mathrm{D}_{3}$ synthesis, altered transcription rate, mRNA stability, substrate affinity and protein instability [16]. Linkage disequilibrium and more complex gene-gene or gene-environment interactions may affect the gene's regulation and warrant further investigations.

For the three intronic SNPs of the VDR genes, rs1544410, rs7975232, and rs731236 (also known as Bsml, Apal, and Taql, respectively), associations with the VD status and also with T2D risk 


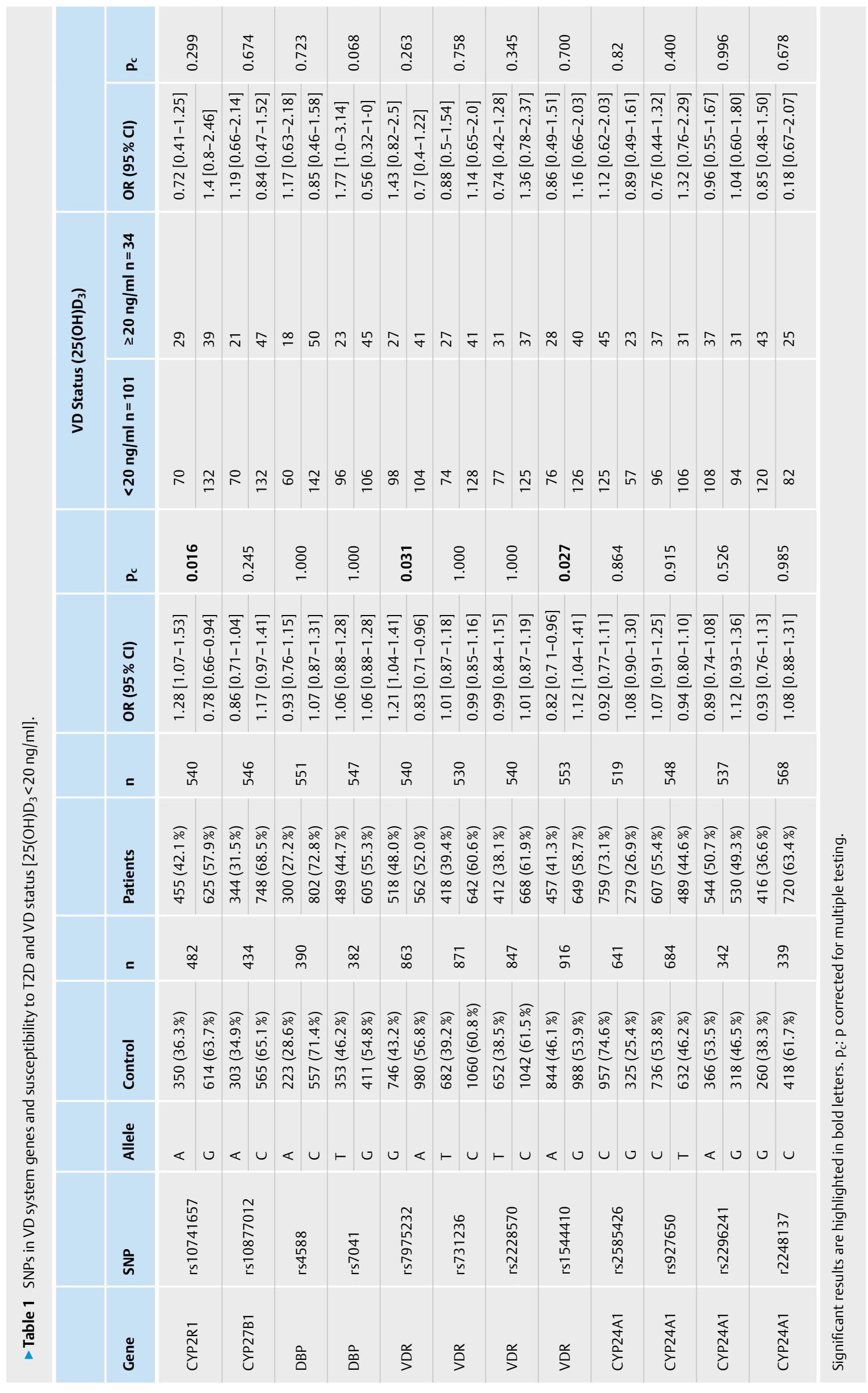




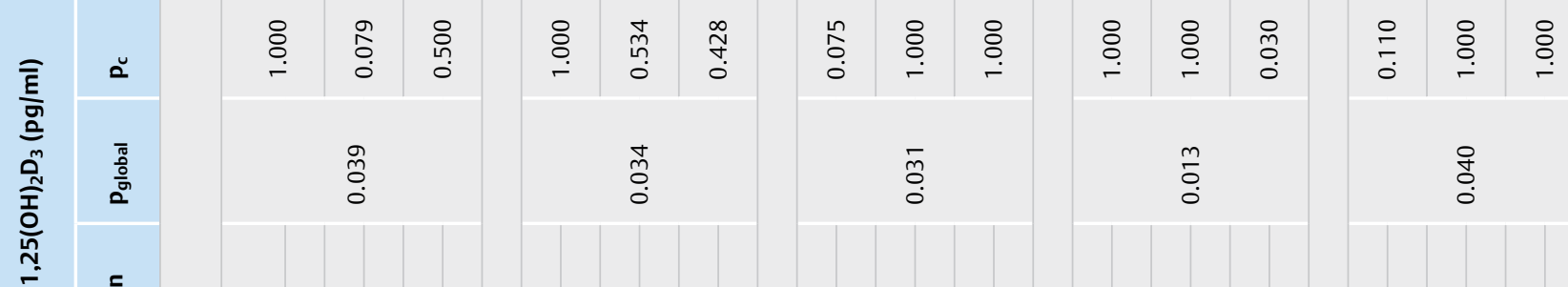

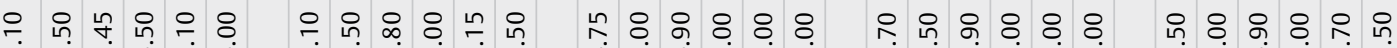
ச่

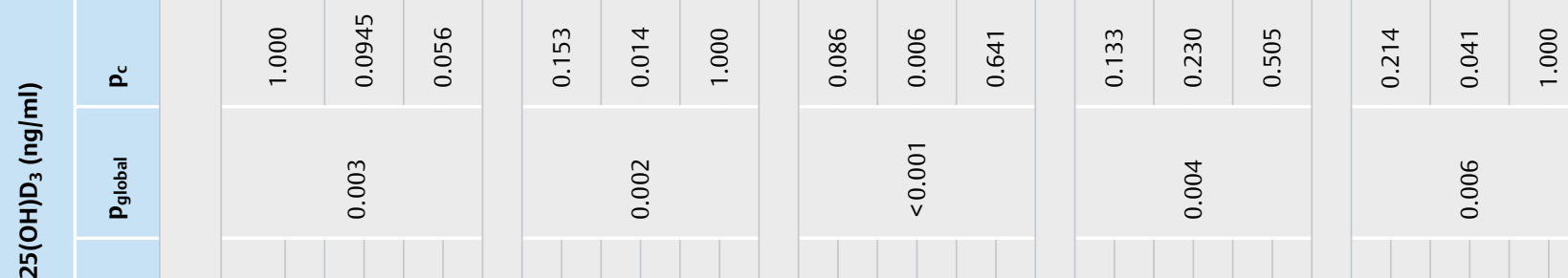

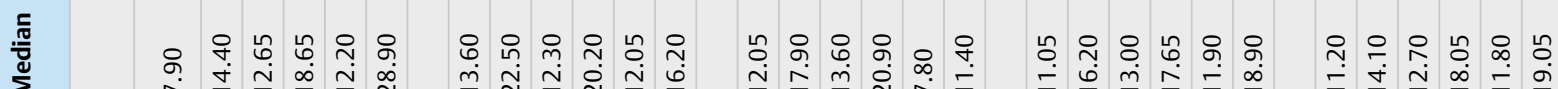

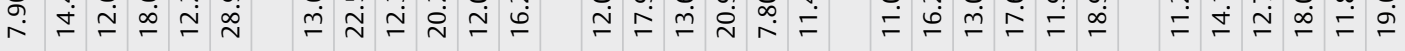

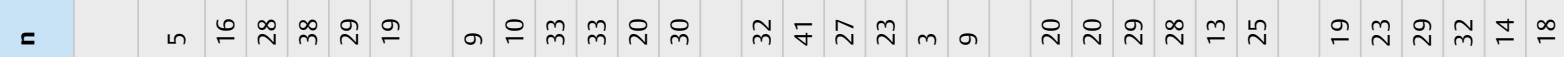

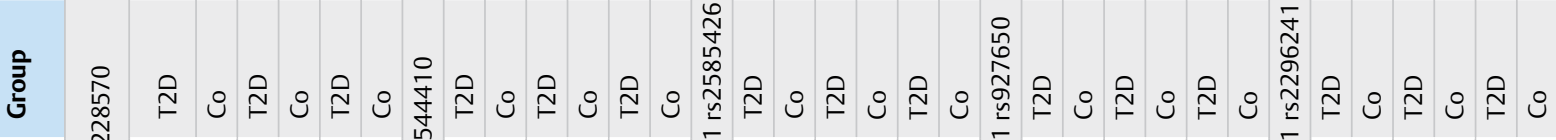

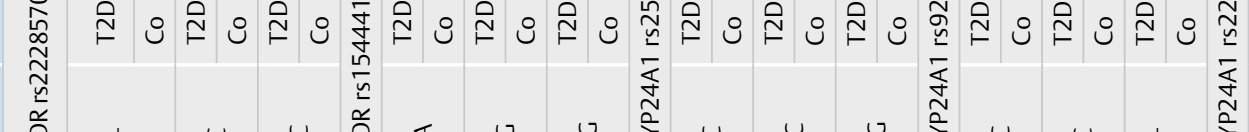

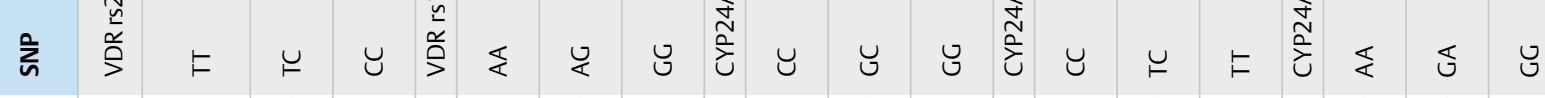

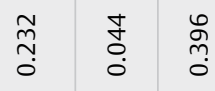

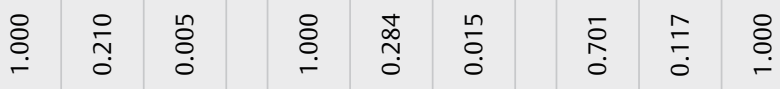

$\stackrel{\substack{0 \\ 0}}{0}$

$\stackrel{\infty}{\leftrightarrow} \stackrel{0}{0}$

$\stackrel{8}{\circ}$

$\stackrel{0}{\circ}$

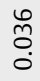

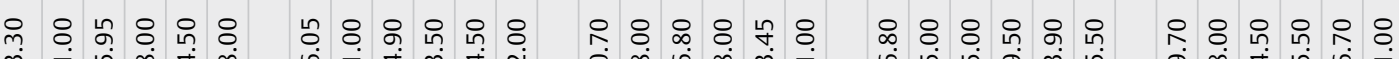
そ் ந்

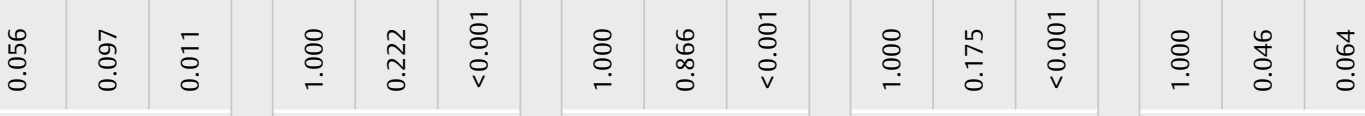

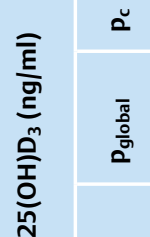
¿े.

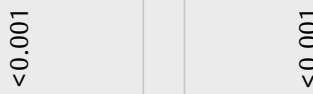

$\bar{\vdots}$

$\bar{s}$

들

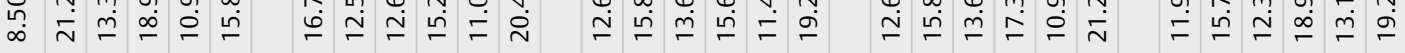

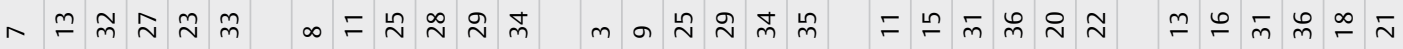

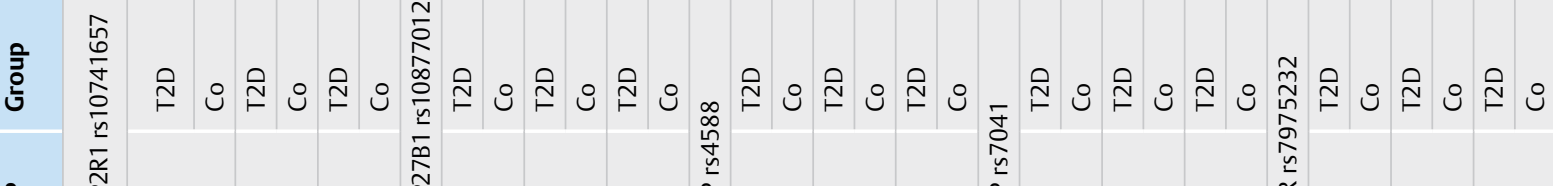

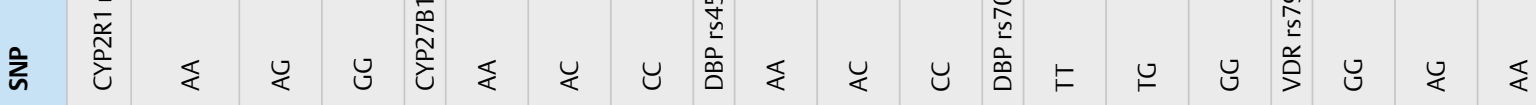




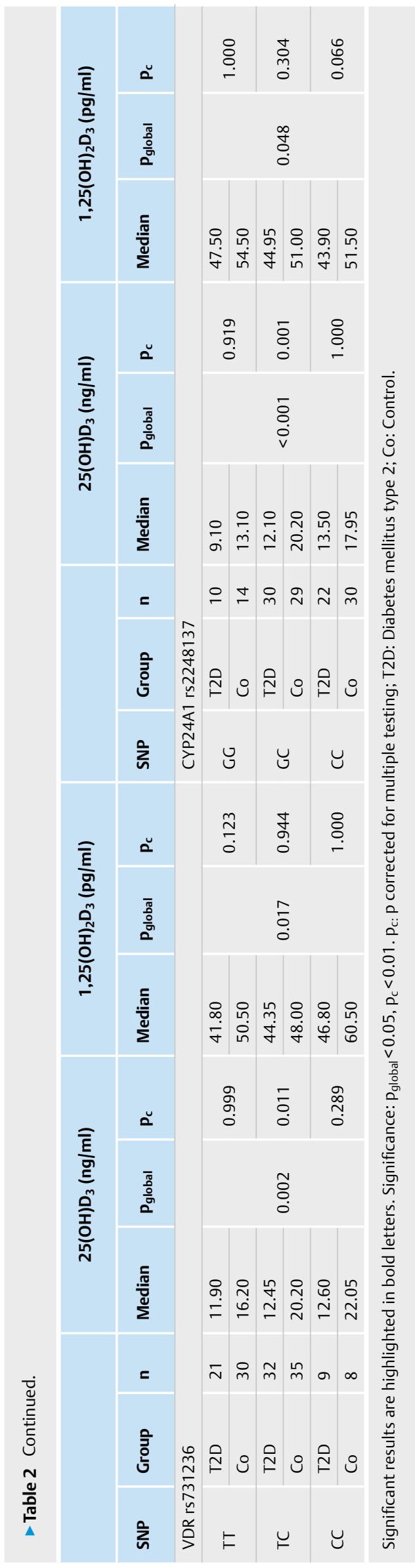

have been described [17-20] whereas other studies did not find this [21-25]. The prevalence of T2D was found higher for carriers of the rs1544410 "A" allele in an Indian [19] and German cohorts [17] but for the " $G$ " allele in East Asians [20]. The heterogeneity of previous study results indicates a high variability of the genetic impact. Our study results present VDR 7975232 "G" VDR rs1544410 " $G$ " as a risk factor for T2D but none of them was associated with significant changes neither of VD status nor VD concentrations.

In contrast, we found lower $25(\mathrm{OH}) \mathrm{D}_{3}$ concentrations associated with the genotypes CYP27B1 rs10877012 "CC", DBP rs4588 “CC”, DBP rs7041 “GG”, CYP24A1 rs2585426 “CG” and CYP24A1 rs2248137 "CG" in patients. This confirms previous findings for CYP27B1 [26-29]. Since the analyzed SNP is in the promotor region of the CYP27B1 gene lower mRNA concentrations may explain the associations as this has been reported for the genotype "CC" in patients with type 1 diabetes mellitus [30] also leading to lower protein and enzyme activity. For DBP rs4588 "A" allele and "AA" genotype and rs7041 "T" allele and genotype "TT" lower VD concentrations have been reported [7,31-36]. The rs4588 C to A mutation corresponds with a deprivation of the $O$-glycosylation side of threonine [37] it can be hypothesized that hyperglycemia changes $O$-glycosydic modifications which might lower VD concentrations in T2D due to alterations in VD binding affinity $[38,39]$. Hereby VD supplementation improves VD concentrations in patients particularly with the rs4588 "CC" genotype, indicating a better VD binding capacity in case of high substrate availability. Also in healthy subjects the "CC" genotype is associated with higher $25(\mathrm{OH}) \mathrm{D}_{3}$ level in response to VD supplementation [40]. Other genotypes have been found such as the VDR rs1544410 "GG" to be better responders to VD supplementation. Serrano et al. reported the same effect in healthy individuals after VD supplementation with retinol fortified soybean for two month [41].

Also SNPs of the CYP24A1 gene, coding for the VD degrading 24-hydroxylase [42] are associated with lower $25(\mathrm{OH}) \mathrm{D}_{3}$ concentrations. We find lower $25(\mathrm{OH}) \mathrm{D}_{3}$ concentrations for the genotypes rs2585426 "CG" and rs2248137 “CG". Since the genotype rs2585426 "GG" showed a trend for lower $25(\mathrm{OH}) \mathrm{D}_{3}$ concentrations $\left(\mathrm{p}_{\mathrm{c}}=0.087\right)$ the " $G$ " allele can be assumed to mediate this effect presumably via degradation.

None of the analyzed SNPs showed an association with the VD status. Combining the SNP analysis with the VD status also did not detect a significant T2D risk. In our cohort study the potential cause-effect relation leading to associations cannot be clarified. It is possible, that the impact of SNPs and VD insufficiency on T2D risk is independent of each other and not directly linked to the genetic loci that we investigated.

The odds ratio in our cohort study reveals that VD insufficiency has a modest impact on T2D risk and the impact of the SNPs is also relatively small. In conclusion the limited sample size for the VDSNP analysis cannot detect a genetic impact of the VD status in relation to T2D risk. Therefore our results neither prove nor exclude a functional role of VD in T2D risk.

Nimitphong et al. analyzed the effect of DBPSNPs rs 4588 on $D_{3}$ or $D_{2}$ supplementation in healthy subjects and showed a higher increase for the "CC" genotype compared to "AA" and "CA" which is congruent with our findings [40]. However, this effect was limited to $\mathrm{D}_{3}$ supplementation. Two further studies confirm these results, 
but showed a higher relative increase for the genotype DBP rs4588 "AA" $[43,44]$. One supplementation trial in T2D including VDR SNPs detected a low response for the VDR "TT" genotype [25]. This effect was not confirmed in our study which might be due to the limited sample size. Moreover only a modest dose for VD supplementation was used and possible confounding variables like age, biophysical activity, diet, and sun exposure were not addressed.

Still, our results provide preliminary evidence for a genetic control of the response to VD supplementation resulting in variable suppression of PTH in patients with T2D. Until today there is only limited knowledge about the role of VD metabolism genes on the response to VD supplementation in general and in patients with T2D in particular. The PTH plateau threshold for rising $25(\mathrm{OH}) \mathrm{D}_{3}$ levels appears to be fixed and to differ between white and black women [45] and from Chinese [46] implying a genetic mechanism in the parathyroid response to vitamin D.

Recently, a trial from Saudi Arabia recruited 204 T2D subjects for an intervention using $2000 \mathrm{lU} / \mathrm{d}$ cholecalciferol and showed significant improvements of several metabolic parameters of diabetes and lipids that also were related to genotypic variation of the VDR [47]. These findings imply, that in order to achieve optimal cardiometabolic effects any vitamin D supplementation may need to be dosed individually. Such VD effects on the glucometabolism depend on interaction with VDR both in peripheral tissues but also in the central nervous system where receptors and the activating $D_{3}-1 \alpha$-hydroxylase are expressed [48]. Furthermore VD action on the hypothalamus and the arcuate nucleus appears to regulate glucose homeostasis and body weight in animals [49].

Taken together the steroidal hormone vitamin $D$ needs to be further characterized as an adjunct in diabetes treatment. Therefore, additional studies with higher VD doses for supplementation and larger cohorts are desirable.

Our study confirms that vitamin D deficiency is highly prevalent in type 2 diabetes and most patients are also functionally affected by low levels of the active metabolite $1,25(\mathrm{OH})_{2} \mathrm{D}_{3}$. Furthermore vitamin $\mathrm{D}$ system genes affect the risk of type 2 diabetes and $25(\mathrm{OH}) \mathrm{D}_{3}$ concentration. But the cause-effect association remains not clarified. The response to $\mathrm{VD}_{3}$ supplementation is influenced by genotypes regulating their magnitude and persistence of a sufficient vitamin D status and the parathyroid response. In order to confirm these preliminary results follow-up trials are necessary as well as functional studies to identify mechanisms how the VD system affects T2D pathophysiology.

\section{Funding Information}

EU-FP7 program NAIMIT 241447

\section{Conflict of Interest}

The authors declare that they have no conflict of interest.
References

[1] Mezza T, Muscogiuri G, Sorice GP et al. Vitamin D deficiency: A new risk factor for type 2 diabetes? Ann Nutr Metab 2012; 61: 337-348

[2] Lopez ER, Regulla K, Pani MA et al. CYP27B1 polymorphisms variants are associated with type 1 diabetes mellitus in Germans. J Steroid Biochem Mol Biol. 2004; 89-90 155-157

[3] Cheng JB, Levine MA, Bell NH et al. Genetic evidence that the human CYP2R1 enzyme is a key vitamin D 25-hydroxylase. Proc Natl Acad Sci USA 2004; 101: 7711-7715

[4] Zehnder D, Bland R, Walker EA et al. Expression of 25-hydroxyvitamin D3-1alpha-hydroxylase in the human kidney. J Am Soc Nephrol 1999; 10: $2465-2473$

[5] Lips P. Vitamin D physiology. Prog Biophys Mol Biol 2006; 92: 4-8

[6] Sakaki T, Sawada N, Nonaka Y et al. Metabolic studies using recombinant escherichia coli cells producing rat mitochondrial CYP24 CYP24 can convert 1alpha,25-dihydroxyvitamin D3 to calcitroic acid. Eur J Biochem 1999; 262: 43-48

[7] Kurylowicz A, Ramos-Lopez E, Bednarczuk T et al. Vitamin D-binding protein (DBP) gene polymorphism is associated with Graves' disease and the vitamin D status in a Polish population study. Exp Clin Endocrinol Diabetes 2006; 114: 329-335

[8] Strobel F, Reusch J, Penna-Martinez M et al. Effect of a randomised controlled vitamin $\mathrm{D}$ trial on insulin resistance and glucose metabolism in patients with type 2 diabetes mellitus. Horm Metab Res 2014; 46: 54-58

[9] Miller SA, Dykes DD, Polesky HF. A simple salting out procedure for extracting DNA from human nucleated cells. Nucleic Acids Res 1988; 16: 1215

[10] Ross AC, Manson AE, Abrams SA et al. The 2011 report on dietary reference intakes for calcium and vitamin D. Public Health Nutr 2011; 14: $938-939$

[11] Xue A, Wu Y, Zhu Z et al. Genome-wide association analyses identify 143 risk variants and putative regulatory mechanisms for type 2 diabetes. Nat Commun 2018; 9: 2941

[12] Jorde R, Schirmer H, Wilsgaard T et al. Polymorphisms related to the serum 25-hydroxyvitamin D level and risk of myocardial infarction, diabetes, cancer and mortality. The Tromso Study. PLoS One 2012; 7: e37295

[13] Yuan S, Jiang X, Michaëlsson $K$ et al. Genetic prediction of serum 25-hydroxyvitamin $\mathrm{D}$, calcium, and parathyroid hormone levels in relation to development of type 2 diabetes: A mendelian randomization study. Diabetes Care 2019; 42: 2197-2203

[14] Wang T], Zhang F, Richards JB et al. Common genetic determinants of vitamin $D$ insufficiency: A genome-wide association study. Lancet 2010; 376: 180-188

[15] Ye Z, Sharp S], Burgess $S$ et al. Association between circulating 25-hydroxyvitamin $D$ and incident type 2 diabetes: A mendelian randomisation study. Lancet Diabetes Endocrinol 2015; 3: 35-42

[16] Ramos-Lopez E, Bruck P, Jansen T et al. CYP2R1 (vitamin D 25-hydroxylase) gene is associated with susceptibility to type 1 diabetes and vitamin D levels in Germans. Diabetes Metab Res Rev 2007; 23: 631-636

[17] Ortlepp JR, Lauscher J, Hoffmann R et al. The vitamin D receptor gene variant is associated with the prevalence of type 2 diabetes mellitus and coronary artery disease. Diabet Med 2001; 18: 842-845

[18] Bid HK, Konwar R, Aggarwal CG et al Vitamin D receptor (Fokl, Bsml and Taql) gene polymorphisms and type 2 diabetes mellitus: a North Indian study. Indian J Med Sci 2009; 63: 187-194

[19] Mukhopadhyaya PN, Acharya A, Chavan Y et al. Metagenomic study of single-nucleotide polymorphism within candidate genes associated with type 2 diabetes in an Indian population. Genet Mol Res 2010; 9: 2060-2068 
[20] Li L, Wu B, Liu JY et al. Vitamin D receptor gene polymorphisms and type 2 diabetes: A meta-analysis. Arch Med Res 2013; 44: 235-241

[21] Ogunkolade BW, Boucher BJ, Prahl JM et al. Vitamin D receptor (VDR) $\mathrm{mRNA}$ and VDR protein levels in relation to vitamin $\mathrm{D}$ status, insulin secretory capacity, and VDR genotype in Bangladeshi Asians. Diabetes 2002; 51: 2294-2300

[22] Malecki MT, Frey J, Moczulski D et al. Vitamin D receptor gene polymorphisms and association with type 2 diabetes mellitus in a Polish population. Exp Clin Endocrinol Diabetes 2003; 111: 505-509

[23] Dilmec F, Uzer E, Akkafa F et al. Detection of VDR gene Apal and Taql polymorphisms in patients with type 2 diabetes mellitus using PCR-RFLP method in a Turkish population. J Diabetes Complicat 2010; 24: $186-191$

[24] Wang Q, Xi B, Reilly KH et al. Quantitative assessment of the associations between four polymorphisms (Fokl, Apal, Bsml, Taql) of vitamin $\mathrm{D}$ receptor gene and risk of diabetes mellitus. Mol Biol Rep 2012; 39: 9405-9414

[25] Neyestani TR, Djazayery A, Shab-Bidar S et al. Vitamin D receptor Fok-I polymorphism modulates diabetic host response to vitamin $D$ intake: Need for a nutrigenetic approach. Diabetes Care 2013; 36: 550-556

[26] Ramos-Lopez E, Kahles H, Weber $\mathrm{S}$ et al. Gestational diabetes mellitus and vitamin D deficiency: Genetic contribution of CYP27B1 and CYP2R1 polymorphisms. Diabetes Obes Metab 2008; 10: 683-685

[27] Hypponen E, Berry DJ, Wjst M et al. Serum 25-hydroxyvitamin D and IgE - a significant but nonlinear relationship. Allergy 2009; 64: 613-620

[28] Signorello LB, Shi J, Cai Q et al. Common variation in vitamin D pathway genes predicts circulating 25-hydroxyvitamin D Levels among African Americans. PLoS One 2011; 6: e28623

[29] Hussein AG, Mohamed RH, Alghobashy AA. Synergism of CYP2R1 and CYP27B1 polymorphisms and susceptibility to type 1 diabetes in Egyptian children. Cell Immunol 2012; 279: 42-45

[30] Ramos-Lopez E, Bruck P, jansen T et al. CYP2R1-, CYP27B1- and CYP24-mRNA expression in German type 1 diabetes patients. J Steroid Biochem Mol Biol 2007; 103: 807-810

[31] Simon KC, Munger KL, Kraft P et al. Genetic predictors of 25-hydroxyvitamin D levels and risk of multiple sclerosis. J Neurol 2011; 258: 1676-1682

[32] Lu L, Sheng H, Li H et al. Associations between common variants in GC and DHCR7/NADSYN1 and vitamin D concentration in Chinese Hans. Hum Genet 2012; 131: 505-512

[33] Azad AK, Bairati I, Qiu X et al. Genetic sequence variants in vitamin D metabolism pathway genes, serum vitamin $\mathrm{D}$ level and outcome in head and neck cancer patients. Int J Cancer 2013; 132: 2520-2527

[34] Carpenter TO, Zhang JH, Parra E et al. Vitamin D binding protein is a key determinant of 25 -hydroxyvitamin $D$ levels in infants and toddlers. J Bone Miner Res 2013; 28: 213-221

[35] Engelman CD, Meyers KJ, lyengar SK et al. Vitamin D intake and season modify the effects of the GC and CYP2R1 genes on 25-hydroxyvitamin D concentrations. J Nutr 2013; 143: 17-26
[36] Santos BR, Mascarenhas LP, Boguszewski MC et al. Variations in the vitamin $\mathrm{D}$-binding protein (DBP) gene are related to lower 25 -hydroxyvitamin D levels in healthy girls: A cross-sectional study. Horm Res Paediatr 2013; 79: 162-168

[37] Coppenhaver DH, Sollenne NP, Bowman BH. Post-translational heterogeneity of the human vitamin D-binding protein (group-specific component). Arch Biochem Biophys 1983; 226: 218-223

[38] Ravnsborg T, Olsen DT, Thysen AH et al. The glycosylation and characterization of the candidate Gc macrophage activating factor. Biochim Biophys Acta 2010; 1804: 909-917

[39] Testa R, Vanhooren V, Bonfigli AR et al. N-glycomic changes in serum proteins in type 2 diabetes mellitus correlate with complications and with metabolic syndrome parameters. PLoS One 2015; 10: e0119983

[40] Nimitphong H, Saetung S, Chanprasertyotin S et al. Changes in circulating 25 -hydroxyvitamin $\mathrm{D}$ according to vitamin $\mathrm{D}$ binding protein genotypes after vitamin $\mathrm{D}(3)$ or $\mathrm{D}(2)$ supplementation. Nutr J 2013; 12: 39

[41] Serrano JC, De Lorenzo D, Cassanye A et al. Vitamin D receptor Bsml polymorphism modulates soy intake and 25-hydroxyvitamin $D$ supplementation benefits in cardiovascular disease risk factors profile. Genes Nutr 2013; 8: 561-569

[42] Jones G, Prosser DE, Kaufmann M. 25-Hydroxyvitamin D-24-hydroxylase (CYP24A1): Its important role in the degradation of vitamin D. Arch Biochem Biophys 2012; 523: 9-18

[43] Fu L, Yun F, Oczak M et al. Common genetic variants of the vitamin D binding protein (DBP) predict differences in response of serum 25-hydroxyvitamin D [25(OH)D] to vitamin D supplementation. Clin Biochem 2009; 42: 1174-1177

[44] Muindi JR, Adjei AA, Wu ZR et al. Serum vitamin D metabolites in colorectal cancer patients receiving cholecalciferol supplementation: Correlation with polymorphisms in the vitamin $D$ genes. Horm Cancer 2013; 4: 242-250

[45] Aloia JF, Chen DG, Chen $\mathrm{H}$. The 25(OH)D/PTH threshold in black women. J Clin Endocrinol Metab 2010; 95: 5069-5073

[46] Yao P, Sun L, Lu L et al. Effects of Genetic and nongenetic factors on total and bioavailable $25(\mathrm{OH}) \mathrm{D}$ responses to vitamin D supplementation. J Clin Endocrinol Metab 2017; 102: 100-110

[47] Al-Daghri NM, Mohammed AK, Al-Attas OS et al. Vitamin D receptor gene polymorphisms modify cardiometabolic response to vitamin D supplementation in T2DM Patients. Sci Rep 2017; 7: 8280

[48] Eyles DW, Smith S, Kinobe R et al. Distribution of the vitamin D receptor and 1 alpha-hydroxylase in human brain. J Chem Neuroanat 2005; 29: 21-30

[49] Sisley SR, Arble DM, Chambers AP et al. Hypothalamic vitamin D improves glucose homeostasis and reduces weight. Diabetes 2016; 65: 2732-2741 